\title{
Effect of Water Stress on the Growth and Development of Amaranthus spinosus, Leptochloa chinensis, and Rice
}

\author{
Bhagirath S. Chauhan, Seth B. Abugho \\ Crop and Environmental Sciences Division, International Rice Research Institute, Los Baños, Philippines. \\ Email: b.chauhan@irri.org
}

Received March $5^{\text {th }}, 2013$; revised April 25 ${ }^{\text {th }}, 2013$; accepted May $10^{\text {th }}, 2013$

Copyright (C) 2013 Bhagirath S. Chauhan, Seth B. Abugho. This is an open access article distributed under the Creative Commons Attribution License, which permits unrestricted use, distribution, and reproduction in any medium, provided the original work is properly cited.

\begin{abstract}
Drought is the most important abiotic constraint in rainfed rice systems. In these systems, Amaranthus spinosus and Leptochloa chinensis are the dominant weed species, which may reduce the available water to rice by competition and cause water stress in the crop. Two studies were conducted in a greenhouse to evaluate the growth response of $A$. spinosus and rice and $L$. chinensis and rice to water stress. The water stress treatments were $12.5 \%, 25 \%, 50 \%, 75 \%$, and $100 \%$ of field capacity and the plants were grown until weed maturity (i.e., 63 days from seeding). Rice plants did not survive at $12.5 \%$ and $25 \%$ of field capacity, but both weed species survived in all the treatments. Both weed species produced a significant number of tillers/branches and leaves even at the lowest soil water content. The maximum amount of total shoot biomass produced by weed plants was 2.5 to 3 times more than that of rice plants. The soil water content to achieve $50 \%$ of the maximum aboveground biomass was $47 \%-50 \%$ of field capacity for rice, whereas it was $39 \%$ and $31 \%$ of field capacity for A. spinosus and L. chinensis, respectively. A. spinosus plants responded to increasing water stress with increased leaf weight ratio, whereas the leaf weight ratio of $L$. chinensis decreased with increases in water stress. The ability of $A$. spinosus and $L$. chinensis to produce shoot biomass under water-stressed conditions suggests that weed management strategies are needed that can minimize weed survival in water-limited environments. These strategies may include the use of weed-competitive and drought-tolerant cultivars, high seeding rates, and optimum timing of fertilizers.
\end{abstract}

Keywords: Biomass; Soil Moisture; Weed; Rainfed; Drought

\section{Introduction}

Water stress or drought is one of the most important abiotic constraints in rice, reducing yield on 23 million (M) ha of area in South and Southeast Asia [1,2]. In Asia alone, the average loss in rice production in years of drought can exceed one billon US dollars. In water-limited regions, drought risk reduces yield because growers avoid investing money in inputs when they fear crop loss $[2,3]$. In irrigated areas, too, water shortage is becoming an increasing problem because of the rising demand for water in urban areas. Water shortage has been historically associated with food shortage, especially in Asia and Africa [3]. By 2025, 13 Mha of irrigated wetland rice in Asia may experience physical water scarcity and 22 Mha of irrigated dry-season rice may suffer from economic water scarcity [4]. Therefore, limited water availability in the future may decrease the capacity of growers to irrigate their fields frequently in irrigated areas, resulting in water stress for crops as well as weeds $[5,6]$. In rainfed areas, growers depend on rain and the sporadic rainfall events may result in water stress at any time during the growing season.

Growers in many parts of Asia are shifting their rice production systems from traditional transplanting of seedlings to direct-seeded systems in response to water and labor scarcities. Weeds, however, are the most important biological constraint in direct-seeded rice production systems [7] as weeds and rice emerge simultaneously and there is no standing water at the time of crop emergence. In water-limited fields, weeds may reduce the available water to crops by competition and cause water stress in crops [8]. Amaranthus spinosus L. (spiny amaranth, a $\mathrm{C}_{4}$ broadleaf species) and Leptochloa chinensis (L.) Nees (Chinese sprangletop, a $\mathrm{C}_{4}$ grass species) are amongst the dominant weed species occurring in direct-seeded rice $\left(\mathrm{C}_{3}\right.$ species $)$ systems [9-13]. A. spinosus was reported to occur in 15 countries in dry-seeded rice systems [14]. It is a prolific seed producer and the spines 
present on the plants cause management problems during hand weeding and hand harvest. L. chinensis has the ability to grow well in both flooded and upland environments. The widespread introduction of direct-seeded systems, coupled with herbicide use, is thought to be responsible for the increased infestation of this weed in rice. In Malaysia, for example, $L$. chinensis became widespread with the change to direct-seeding of rice from transplanting [15]. Similarly, in Sri Lanka, repeated use of bispyribacsodium has resulted in a shift in the composition of the weed flora to dominance by L. chinensis [16].

Amaranthus spinosus and L. chinensis are problematic weed species in rice culture; however, published information is limited concerning the growth and development of these weeds to water stress. In general, $\mathrm{C}_{4}$ species require less water than $\mathrm{C}_{3}$ species because of the higher carbon dioxide uptake rates and greater stomatal resistance to water loss [17]. Under drought, plants with the $\mathrm{C}_{4}$ carbon fixation pathway have a competitive advantage over plants possessing the more common $\mathrm{C}_{3}$ pathway $[18,19]$. Therefore, A. spinosus and L. chinensis are expected to be more tolerant of water stress than the rice crop. The aim of our study was to determine the effect of water stress on the growth and development of $A$. spinosus, L. chinensis, and rice.

\section{Materials and Methods}

Seeds of $A$. spinosus and $L$. chinensis were collected in May 2012 from rice fields in Los Baños, Philippines $\left(14^{\circ} 10^{\prime} \mathrm{N}, 121^{\circ} 13^{\prime} \mathrm{E}\right)$. Soil used in the study was collected from upland rice fields, autoclaved, and passed through a $3-\mathrm{mm}$ sieve. Soil $(9 \mathrm{~kg})$ was placed in plastic pots $(30 \mathrm{~cm}$ in diameter and $25 \mathrm{~cm}$ in height). Experiments were conducted separately for each weed species. In each pot, two plants of weeds and two plants of rice (cv. Apo in the A. spinosus experiment and cv. Rc222 in the $L$. chinensis experiment) were grown together. The distance between the plants was $10 \mathrm{~cm}$ and the plants were about $8 \mathrm{~cm}$ away from the edge of the pot. For this, two and four seeds of rice and weeds, respectively, were planted in the soil ( $1 \mathrm{~cm}$ deep for rice and $2 \mathrm{~mm}$ deep for weeds). Immediately after sowing, the pots were saturated with a sprinkler system. The seedlings emerged 3 to 4 days after sowing and were thinned to two plants of each species per pot immediately after emergence. Nitrogen at 100 $\mathrm{kg} \cdot \mathrm{ha}^{-1}$ was applied before irrigation in two equal splits at 14 and 28 days after planting (DAP).

Experiments were modified from studies by Chauhan and Johnson [20] and water stress treatments started at 7 DAP. Water treatments were $12.5 \%, 25 \%, 50 \%, 75 \%$, and $100 \%$ of soil field capacity (FC). To determine FC [21], four pots were filled with $9 \mathrm{~kg}$ of soil. The weight of the pots containing the dry soil was measured. Pots were watered, allowed to drain for 24 hours, and re- weighed to determine the field (pot) capacity. The amount of $100 \%$ of FC was $1.0 \mathrm{~L}$ water, and the volume of water was applied at 3-day intervals. The pots were arranged in a greenhouse as a completely randomized design with four replications. Experiments with each weed species were conducted two times (planting time of A. spinosus experiment: first week of July 2012 and second week of September 2012, and planting time of $L$. chinensis experiment: second week of July 2012 and third week of September 2012). Minimum and maximum temperatures recorded in the greenhouse were $24^{\circ} \mathrm{C}$ and $40^{\circ} \mathrm{C}$, respectively, and photosynthetically active photon density was $1300 \mathrm{~mol} \cdot \mathrm{m}^{-2} \cdot \mathrm{s}^{-1}$. Experiments were conducted in natural light.

In all experiments, plant height and number of tillers (or branches for A. spinosus) and leaves per plant were determined at 14, 21, 28, 35, 42, 49, 56, and 63 DAP. Plant height was measured from the soil surface to the tip of the uppermost leaf. At weed maturity (63 DAP for both weed species), all plants were removed from the pots and separated into different parts: stems, leaves, and inflorescence (for weeds only). These plant parts were placed in separate paper bags and dried in an oven at $70^{\circ} \mathrm{C}$ for 72 hours. In addition, leaf weight ratio was estimated by dividing the amount of leaf biomass by total

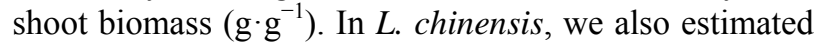
inflorescence weight ratio by dividing the amount of inflorescence biomass by total shoot biomass $\left(\mathrm{g} \cdot \mathrm{g}^{-1}\right)$.

Data were subjected to analysis of variance (ANOVA). Due to a lack of interactions between treatment and experimental run [22], the data were pooled over the experimental runs (therefore, a total of eight replications). Plant height, leaf number, and tiller/branch number data were analyzed using a three-parameter sigmoid model: $y=a\left\{1+\mathrm{e}^{\left[-\left(x-x_{50}\right) / b\right]}\right\}$, where $a$ is the maximum height, leaf number, or tiller/branch number; $x_{50}$ is the time (DAP) to reach $50 \%$ of the final height, leaf number, or tiller/branch number; and $b$ is the slope at time $x$. The same model was fitted to the leaf, stem, and total shoot biomass of all species and leaf weight ratio of $L$. chinensis, where $a$ is the maximum biomass or leaf weight ratio, $x_{50}$ is the soil water content (SWC) to reach $50 \%$ of the maximum biomass or leaf weight ratio, and $b$ is the slope at SWC $x$. Leaf weight ratio data of $A$. spinosus were analyzed using an exponential model, $\mathrm{y}=a \mathrm{xe}^{-b x}$, where $a$ is the intercept and $b$ is the slope at SWC $x$.

\section{Results}

\subsection{Amaranthus spinosus}

Soil moisture content (percent of FC) greatly affected plant height and growth of rice and $A$. spinosus. The plant height of both species at different SWC increased 
in a sigmoid manner over the experimental period (Figures 1(a) and (d)). Rice plants had a maximum height of $79 \mathrm{~cm}$ at $100 \%$ of FC, whereas this was $68 \mathrm{~cm}$ at $50 \%$ of FC (Figure 1(a) and Table 1). Although rice plants achieved the maximum height of 59 and $56 \mathrm{~cm}$ at 25 and $12.5 \%$ of FC, respectively, these plants could not survive until 63 DAP and they died before the final harvest. The slope $(b)$ value was maximum at $100 \%$ of FC and it decreased with decreases in SWC (Table 1).

Amaranthus spinosus plants had a maximum height of $137 \mathrm{~cm}$ at $100 \%$ of FC (Figure 1(d); Table 1). Decreases in SWC decreased plant height of the weed, but, unlike rice, the weed plants survived at all levels of SWC until the harvest period (63 DAP). At $25 \%$ and $12.5 \%$ of FC, A. spinosus still produced plants with a height of 30 and 25 $\mathrm{cm}$, respectively. The slope (b) was similar at $50 \%$ or greater FC and it decreased drastically at $25 \%$ and $12.5 \%$ of FC (Figure 1(d); Table 1).

Rice plants produced a maximum number of $19-20$ leaves plant ${ }^{-1}$ at $75 \%$ and $100 \%$ of FC (Figure 1(b); Table 1). The leaf production of rice declined with decreases in $\mathrm{FC}$ below $75 \%$. At $25 \%$ and $12.5 \%$ of $\mathrm{FC}$, rice plants produced a maximum of 13 and 10 leaves plant ${ }^{-1}$; however, these plants died by 63 DAP. The slope $(b)$ of leaf production was similar at $50 \%$ or higher $\mathrm{FC}$ and it decreased below $50 \%$ of FC (Table 1). At $50 \%$ or higher FC, rice plants took a similar time ( 22 to 24 days) to produce $50 \%$ of the maximum leaves. At $12.5 \%$ and $25 \%$ of FC, rice plants produced $50 \%$ of the maximum leaves in only 16 to 17 days (Table $\mathbf{1}$ ).

Amaranthus spinosus plants produced the maximum number of leaves ( 147 plant $^{-1}$ ) when grown at $100 \%$ of FC; however, the number of leaves produced by the weed at 75 and $100 \%$ of FC was statistically similar (Figure 1(e); Table 1). The weed also produced a similar number of leaves ( 46 to 51 plant $^{-1}$ ) at $12.5 \%$ and $25 \%$ of FC. The slope of leaf production was similar at $50 \%$ or higher FC and it decreased below $25 \%$ of FC. The weed plants took a similar time (31 to 32 days) at 75 and $100 \%$ of FC to produce $50 \%$ of the maximum number of leaves $\left(x_{50}\right)$. Below $75 \%$ of FC, the weed took less time to produce $50 \%$ of the maximum number of leaves (Table 1).

As estimated from the fitted model, rice plants produced an average of 4 tillers plant ${ }^{-1}$ at $100 \%$ of FC, which was similar to the tillers produced at $75 \%$ of FC (Figure 1(c); Table 1). Although rice plants produced an average of 3 tillers plant ${ }^{-1}$ at $12.5 \%$ and $25 \%$ of FC, these plants did not survive until 63 DAP. The slope of tiller production was similar at different SWC (Table 1). Similarly, the time $\left(x_{50}\right)$ taken to produce $50 \%$ of the maximum number of tillers was similar at different SWC (Figure 1(c); Table 1).

Amaranthus spinosus plants produced a similar number of branches (24 to 25 plant $^{-1}$ ) at $50 \%$ or higher FC (Figure 1(f); Table 1). With decreases in FC below $50 \%$, however, the number of branches also declined. At 12.5 and $25 \%$ of FC, A. spinosus produced 11 branches plant $^{-1}$. A similar response was observed for the slope $(b)$ and time $\left(x_{50}\right)$ taken to produce $50 \%$ of the maximum number of branches (Figure 1(f); Table 1). The $x_{50}$, for example, was 33 to 36 days at $50 \%$ and higher FC and it was only 21 to 22 days at $12.5 \%$ and $25 \%$ of FC.

Table 1. Parameter estimates of a three-parameter sigmoid model $\left(y=a /\left\{1+\mathrm{e}^{[-(x-x 50) / b]}\right\}\right.$, where $a$ is the maximum height, leaf number, or tiller/branch number; $x_{50}$ is the time (days after planting) to reach $50 \%$ of the final height, leaf number, or tiller/branch number; and $b$ is the slope at time $x$ ) fitted to plant height, leaf number, and tiller or branch number of rice and Amaranthus spinosus when grown at different soil water contents.

\begin{tabular}{|c|c|c|c|c|c|c|c|c|c|c|c|c|}
\hline \multirow{2}{*}{$\begin{array}{c}\text { Field } \\
\text { capacity (\%) }\end{array}$} & $a$ & $b$ & $x_{50}$ & $R^{2}$ & $a$ & $b$ & $x_{50}$ & $R^{2}$ & $a$ & $b$ & $x_{50}$ & $R^{2}$ \\
\hline & \multicolumn{4}{|c|}{ Plant height $\left(\mathrm{cm} \mathrm{plant}^{-1}\right)$} & \multicolumn{4}{|c|}{ Leaves (number plant ${ }^{-1}$ ) } & \multicolumn{4}{|c|}{ Tillers/branches (number plant ${ }^{-1}$ ) } \\
\hline \multicolumn{13}{|c|}{ Rice } \\
\hline 100 & $79(2.1)^{\mathrm{a}}$ & $8.4(0.9)$ & $21.7(0.9)$ & 0.99 & $19.7(1.8)$ & $7.6(3.1)$ & $22.0(3.2)$ & 0.90 & $4.0(0.2)$ & $5.6(1.5)$ & $19.3(1.6)$ & 0.96 \\
\hline 75 & $75(1.6)$ & $7.6(0.7)$ & $21.0(0.7)$ & 0.99 & $19.0(1.6)$ & $8.9(2.9)$ & $23.6(3.0)$ & 0.93 & $3.7(0.1)$ & $5.5(1.3)$ & $19.0(1.4)$ & 0.97 \\
\hline 50 & $68(0.7)$ & $6.2(0.4)$ & $19.2(0.4)$ & 0.99 & $16.4(0.7)$ & $7.5(1.4)$ & $21.7(1.5)$ & 0.98 & $3.5(0.1)$ & $4.6(0.9)$ & $18.8(0.9)$ & 0.98 \\
\hline 25 & $59(1.0)$ & $5.4(0.5)$ & $17.3(0.5)$ & 0.99 & $13.3(0.8)$ & $4.8(1.9)$ & $17.3(1.8)$ & 0.94 & $3.3(0.1)$ & $4.0(0.7)$ & $17.4(0.7)$ & 0.99 \\
\hline 12.5 & $56(1.0)$ & $5.2(0.5)$ & $16.6(0.5)$ & 0.99 & $10.4(1.1)$ & $3.8(2.7)$ & $16.1(2.6)$ & 0.94 & $3.0(0.2)$ & $5.0(1.4)$ & $18.6(1.4)$ & 0.97 \\
\hline \multicolumn{13}{|c|}{ Amaranthus spinosus } \\
\hline 100 & $137(13.1)$ & $12.7(1.2)$ & $49.2(2.9)$ & 0.99 & $147(11.7)$ & $7.9(1.9)$ & $32.4(2.4)$ & 0.97 & $25.4(2.1)$ & $9.9(1.9)$ & $35.5(2.6)$ & 0.98 \\
\hline 75 & $128(15.7)$ & $14.0(1.6)$ & $48.8(4.0)$ & 0.99 & $134(7.7)$ & $8.4(1.5)$ & $30.8(1.8)$ & 0.98 & $23.7(1.6)$ & $9.4(1.6)$ & $33.0(2.1)$ & 0.98 \\
\hline 50 & $73(6.4)$ & $12.5(1.9)$ & $36.5(3.0)$ & 0.99 & $104(5.4)$ & $7.2(1.6)$ & $25.7(1.7)$ & 0.97 & $23.9(2.7)$ & $10.5(2.7)$ & $33.5(3.6)$ & 0.96 \\
\hline 25 & $30(1.2)$ & $4.7(1.2)$ & $19.9(1.2)$ & 0.97 & $51(2.5)$ & $2.7(1.2)$ & $19.4(1.3)$ & 0.94 & $11.2(0.7)$ & $4.1(1.6)$ & $21.9(1.7)$ & 0.94 \\
\hline 12.5 & $25(1.6)$ & $3.4(1.7)$ & $17.9(1.9)$ & 0.90 & $46(3.8)$ & $2.5(1.7)$ & $18.3(2.3)$ & 0.84 & $10.5(0.6)$ & $3.1(1.5)$ & $20.9(1.5)$ & 0.93 \\
\hline
\end{tabular}

${ }^{\mathrm{a}}$ Values in parentheses are standard error of mean. 

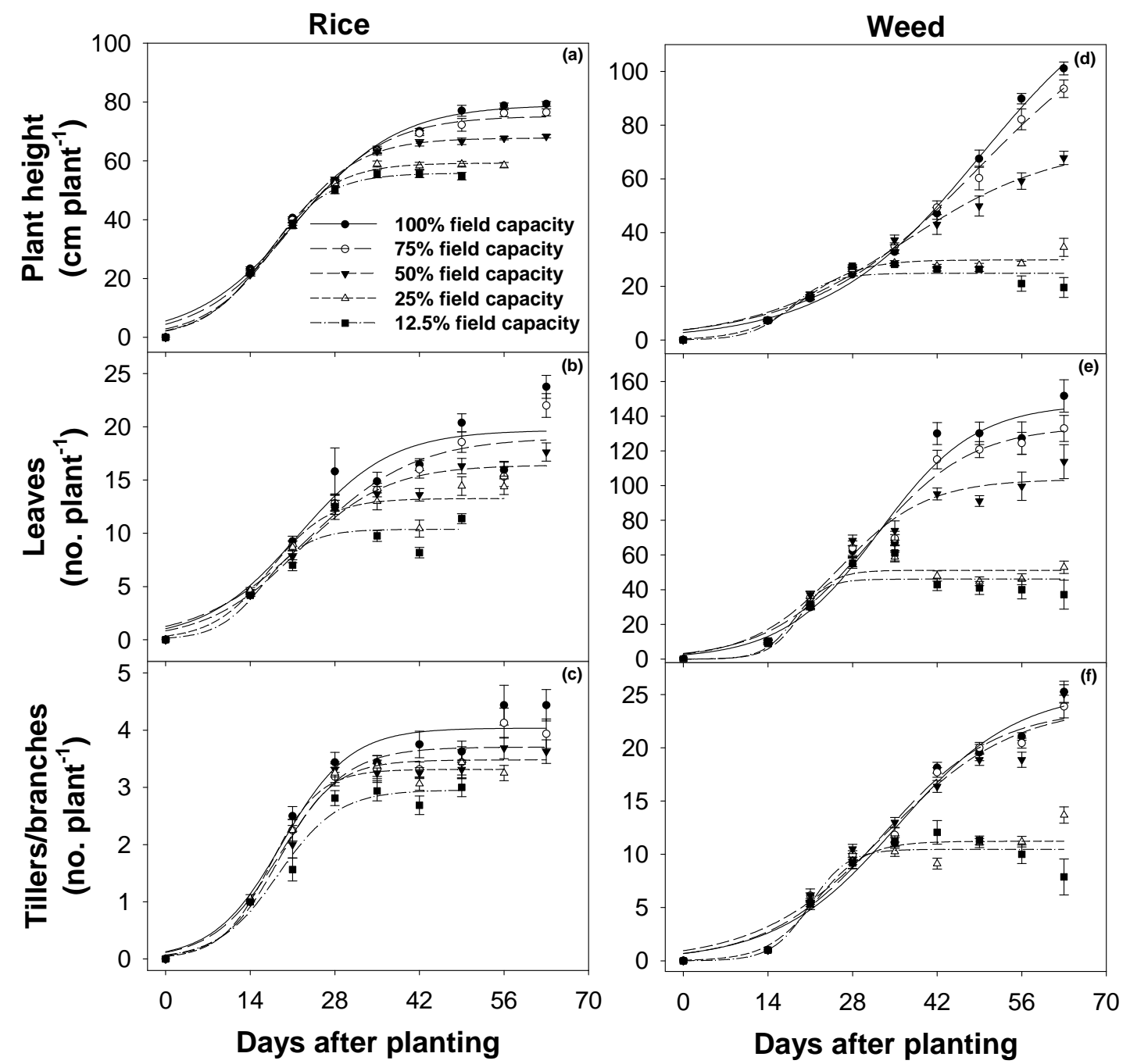

Figure 1. Height (a and d), number of leaves (b and e), and number of tillers or branches (c and $f$ ) of rice and Amaranthus spinosus plants grown over $63 \mathrm{~d}$ after planting in different field capacity regimes. Water stress treatments were imposed at 7 days after planting and vertical bars represent standard error of mean $(n=8)$. The lines represent a three-parameter sigmoid model $\left(y=a /\left\{1+\mathrm{e}^{[-(x-x 50) / b]}\right\}\right)$ fitted to the data. Parameter estimates are shown in Table 1 .

Leaf, stem, and total shoot biomass of rice and $A$ spinosus increased with increases in SWC (Figures 2(a)-(c)). Rice plants did not survive at 25 and $12.5 \%$ of FC and, therefore, there was no biomass at these SWC. The maximum leaf, stem, and total shoot biomass (a) of rice was 1.5, 2.1, and $3.6 \mathrm{~g} \cdot$ plant $^{-1}$, respectively (Table 2). The estimated model predicted that the FC to achieve $50 \%$ of the maximum leaf, stem, and total shoot biomass of rice was $48 \%, 53 \%$, and $50 \%$, respectively. In A. spinosus, however, the corresponding SWC was $25 \%, 42 \%$, and $39 \%$ of FC, respectively (Table 2). The weed plants had a maximum total shoot biomass $(a)$ of $10.6 \mathrm{~g} \cdot$ plant $^{-1}$, which was around 3 times more than that of rice biomass.

As rice plants did not survive at $25 \%$ and $12.5 \%$ of FC, there were only three data points of leaf height ratio and the models did not fit the leaf weight ratio of rice. Leaf weight ratio was higher at $50 \%$ of FC than at $100 \%$ of FC.
Leaf weight ratio values ( \pm standard error of mean) were $0.42 \pm 0.01,0.44 \pm 0.01$, and $0.47 \pm 0.01$ at $100 \%, 75 \%$, and $50 \%$ of FC, respectively. The leaf weight ratio of $A$. pinosus decreased with increases in SWC (Figure 2(d); Table 2).

\subsection{Leptochloa chinensis}

Rice plants had a maximum height of $77 \mathrm{~cm}$ at $100 \%$ of FC and height decreased with decreases in SWC (Figure 3(a); Table 3). As observed in the A. spinosus experiment, rice did not survive until 63 DAS in the L. chinensis experiment, too, at $25 \%$ and $12.5 \%$ of FC. Leptochloa chinensis plants had the maximum height $(147 \mathrm{~cm})$ at $100 \%$ of FC (Figure 3(d); Table 3). Plant height decreased with decreases in FC. At $12.5 \%$ to $25 \%$ of FC, the weed plants were still 63 to $67 \mathrm{~cm}$ tall. The slope $(b)$ was similar 
Table 2. Parameter estimates of a three-parameter sigmoid model $\left(y=a /\left\{1+\mathrm{e}^{[-(x-x 50) / b]}\right\}\right.$, where $a$ is the maximum biomass; $x_{50}$ is the field capacity (\%) to reach $50 \%$ of the final biomass; and $b$ is the slope at field capacity $x$ ) fitted to leaf, stem, and total shoot biomass and an exponential model $\left(y=a \times \mathrm{e}^{-b x}\right)$ fitted to the leaf weight ratio of rice and Amaranthus spinosus when grown at different soil water contents.

\begin{tabular}{ccc}
\hline Parameter estimates & Rice & Weed \\
\hline Leaf biomass $\left(\mathrm{g} \cdot \mathrm{plant}^{-1}\right)$ & $1.53(0.08)^{\mathrm{a}}$ & $2.26(0.26)$ \\
$a$ & $6.8(3.4)$ & $18.3(9.0)$ \\
$b$ & $48.1(2.0)$ & $24.6(7.5)$ \\
$x_{50}$ & 0.99 & 0.93 \\
$R^{2}$ & & $6.88(0.28)$ \\
Stem biomass $\left(\mathrm{g} \cdot\right.$ plant $\left.^{-1}\right)$ & $2.14(0.20)$ & $12.7(1.8)$ \\
$a$ & $10.8(3.9)$ & $42.0(2.4)$ \\
$b$ & $52.9(4.4)$ & 0.99 \\
$x_{50}$ & 0.98 & $10.56(0.47)$ \\
$R^{2}$ & & $13.4(2.0)$ \\
Total shoot biomass $\left(\mathrm{g} \cdot \mathrm{plant}^{-1}\right)$ & $3.63(0.27)$ & $39.1(2.8)$ \\
$a$ & $9.0(3.7)$ & 0.99 \\
$x_{50}$ & $50.1(3.2)$ & $0.593(0.058)$ \\
$R^{2}$ & 0.99 & $0.013(0.003)$ \\
$R^{2}$ & & 0.92 \\
\hline
\end{tabular}

${ }^{\mathrm{a}}$ Values in parentheses are standard error of mean. - Models did not fit.

Table 3. Parameter estimates of a three-parameter sigmoid model $\left(y=a /\left\{1+e^{[-(x-x 50) / b]}\right\}\right.$, where $a$ is the maximum height, leaf number, or tiller number; $x_{50}$ is the time (days after planting) to reach $50 \%$ of the final height, leaf number, or tiller number; and $b$ is the slope at time $x$ ) fitted to plant height, leaf number, and tiller number of rice and Leptochloa chinensis when grown at different soil water contents.

\begin{tabular}{|c|c|c|c|c|c|c|c|c|c|c|c|c|}
\hline \multirow{2}{*}{$\begin{array}{c}\text { Field } \\
\text { capacity }(\%)\end{array}$} & $a$ & $b$ & $x_{50}$ & $R^{2}$ & $a$ & $b$ & $x_{50}$ & $R^{2}$ & $a$ & $b$ & $x_{50}$ & $R^{2}$ \\
\hline & \multicolumn{4}{|c|}{ Plant height $\left(\mathrm{cm} \cdot\right.$ plant $\left.^{-1}\right)$} & \multicolumn{4}{|c|}{ Leaves (number $\cdot$ plant $^{-1}$ ) } & \multicolumn{4}{|c|}{ Tillers (number plant $^{-1}$ ) } \\
\hline \multicolumn{13}{|c|}{ Rice } \\
\hline 100 & $77(2.5)$ & $8.5(1.1)$ & $23.8(1.1)$ & 0.99 & $27.7(1.4)$ & $6.2(1.3)$ & $30.3(1.5)$ & 0.98 & $7.5(0.7)$ & $10.0(2.2)$ & $34.9(3.0)$ & 0.97 \\
\hline 50 & $69(1.5)$ & $6.7(0.7)$ & $21.3(0.7)$ & 0.99 & $24.5(1.0)$ & $4.6(1.0)$ & $26.9(1.1)$ & 0.98 & $6.0(0.2)$ & $6.1(1.0)$ & $27.1(1.1)$ & 0.99 \\
\hline 25 & $63(0.8)$ & $6.0(0.4)$ & $20.0(0.4)$ & 0.99 & $22.1(0.6)$ & $5.2(0.6)$ & $26.1(0.7)$ & 0.99 & $4.8(0.3)$ & $6.1(1.6)$ & $25.1(1.8)$ & 0.97 \\
\hline 12.5 & $55(0.7)$ & $5.0(0.4)$ & $18.1(0.4)$ & 0.99 & $18.4(0.5)$ & $4.1(0.7)$ & $23.4(0.8)$ & 0.99 & $4.0(0.2)$ & $4.2(1.3)$ & $22.4(1.5)$ & 0.96 \\
\hline \multicolumn{13}{|c|}{ Leptochloa chinensis } \\
\hline 75 & $120(4.6)$ & $9.1(0.9)$ & $33.5(1.2)$ & 0.99 & $35.2(2.9)$ & $5.7(2.1)$ & $29.7(2.4)$ & 0.93 & $10.2(1.0)$ & $10.0(1.8)$ & $39.7(2.8)$ & 0.98 \\
\hline 50 & $86(0.8)$ & $5.8(0.3)$ & $27.2(0.3)$ & 0.99 & $37.4(2.6)$ & $5.4(1.7)$ & $29.9(2.0)$ & 0.95 & $9.5(0.7)$ & $8.9(1.7)$ & $36.0(2.2)$ & 0.98 \\
\hline 25 & $67(0.6)$ & $4.2(0.2)$ & $24.6(0.3)$ & 0.99 & $33.5(1.1)$ & $6.4(0.9)$ & $29.1(1.0)$ & 0.99 & $8.8(0.8)$ & $11.3(1.9)$ & $38.2(3.0)$ & 0.98 \\
\hline 12.5 & $63(0.9)$ & $3.7(0.3)$ & $24.0(0.4)$ & 0.99 & $22.8(0.9)$ & $3.9(0.9)$ & $24.0(1.1)$ & 0.97 & $4.7(0.3)$ & $6.2(2.0)$ & $25.2(2.2)$ & 0.94 \\
\hline
\end{tabular}

${ }^{a}$ Values in parentheses are standard error of mean. 


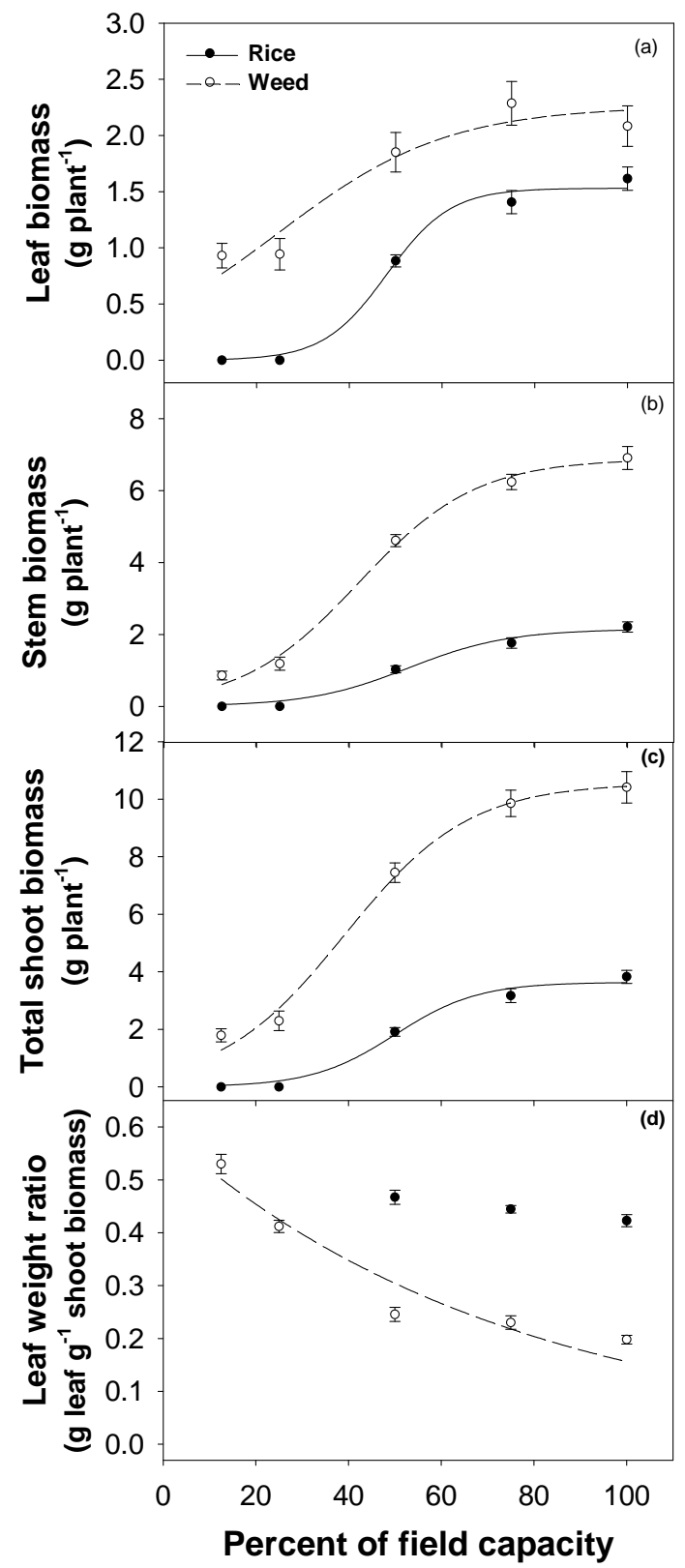

Figure 2. Leaf (a) stem; (b) total shoot; (c) biomass and leaf weight ratio; (d)o f rice and Amaranthus spinosusplants (at 63 days after planting) grown in different field capacity regimes. Vertical bars represent standard error of mean (n $=8)$. The lines represent a three-parameter sigmoid model $\left(y=a /\left\{1+\mathrm{e}^{[-(x-x 50) / b]}\right\}\right)$ fitted to the leaf, stem, and total shoot biomass of rice and $A$. spinosusand an exponential model $\left(y=a \times \mathrm{e}^{-b x}\right)$ fitted to the leaf weight ratio of $A$. spinosus when grown at different soil water contents. Parameter estimates are shown in Table 2.

at $75 \%$ and $100 \%$ of $\mathrm{FC}$, but then it decreased at a lower SWC.

Rice plants produced a similar number of leaves (27 to 28 plant $^{-1}$ ) at $75 \%$ and $100 \%$ of FC (Figure 3(b); Table 3). Although rice produced a maximum of 18 to 22 leaves plant $^{-1}$ at $12.5 \%$ to $25 \%$ of $\mathrm{FC}$, these plants could not survive until 63 DAP. The $x_{50}$ was similar (29 to 30 days) at $75 \%$ and $100 \%$ of FC. At $12.5 \%$ of FC, rice produced $50 \%$ of the maximum leaves at 23 DAP.

Leptochloa chinensis produced a similar number of leaves (34 to 37 plant $^{-1}$ ) at FC from 25 to $100 \%$ (Figure 3(e); Table 3). At $12.5 \%$ of FC, the weed still produced 23 leaves plant ${ }^{-1}$. There was no consistent response of the slope (b) of leaf production to SWC. Similar to the results observed for the number of leaves, the time taken to produce $50 \%$ of the maximum leaves was similar (29 to 30 days) at $\mathrm{FC}$ ranging from $25 \%$ to $100 \%$. At $12.5 \%$ of FC, L. chinensis produced $50 \%$ of the maximum number of leaves at 24 DAP.

Rice produced a similar number of tillers ( 7 to 8 plant $^{-1}$ ) at $75 \%$ and $100 \%$ of $\mathrm{FC}$ and the number of tillers decreased below $75 \%$ of FC (Figure 3(e); Table 3). The time taken to achieve $50 \%$ of the total tillers was similar (32 to 35 days) at $75 \%$ and $100 \%$ of $\mathrm{FC}$, but decreased below $75 \%$ of FC.

Leptochloa chinensis produced an average of 9 to 10 tillers plant ${ }^{-1}$ at $25 \%$ to $100 \%$ of FC (Figure 3(f); Table 3). At $12.5 \%$ of FC, the weed produced an average of 5 tillers plant ${ }^{-1}$. Similarly, the slope (b) was similar at FC ranging from $25 \%$ to $100 \%$. Based on estimates from the sigmoid model, $50 \%$ of the maximum tillers were reached within 36 to 40 days $\left(x_{50}\right)$ at 25 to $100 \%$ of FC and these values were statistically similar. At $12.5 \%$ of FC, $L$. chinensis plants took an average of 25 days to reach $50 \%$ of the maximum tiller production at this moisture content.

Rice and L. chinensis biomass increased with increases in SWC. Rice produced the maximum leaf, stem, and total shoot biomass of $1.9,3.1$, and 4.9 g plant $^{-1}$, respectively, whereas $L$. chinensis produced the maximum leaf, stem, and total shoot biomass of 4.5, 3.6, and $11.8 \mathrm{~g} \cdot$ plant $^{-1}$, respectively (Figures 4(a)-(c); Table 4). Rice plants did not survive until 63 DAP at $25 \%$ and $12.5 \%$ of FC. The $50 \%$ of the maximum total shoot biomass was achieved at $47 \%$ of $\mathrm{FC}$ in rice, whereas this value for $L$. chinensis was only $31 \%$ of FC.

As rice did not survive at $12.5 \%$ and $25 \%$ of $\mathrm{FC}$, leaf weight ratio data of rice could not fit any model. However, the leaf weight ratio decreased with increases in $\mathrm{FC}$ above $25 \%$. The leaf weight ratio ( \pm standard error of mean) at $50 \%, 75 \%$, and $100 \%$ of FC was $0.44 \pm 0.01,0.40 \pm 0.01$, and $0.37 \pm 0.01$, respectively. The leaf weight ratio of $L$. chinensis, on the other hand, increased with increases in SWC (Figure 4(d); Table 4). As estimated from the sigmoid model, the maximum leaf weight ratio of $L$. chinensis was 0.39 . The inflorescence weight ratio of $L$. chinensis increased with increases in water stress. The inflorescence weight ratio ( \pm standard error of mean) at $12.5 \%$, $25 \%, 50 \%, 75 \%$, and $100 \%$ of FC was $0.70 \pm 0.05,0.57 \pm$ $0.04,0.40 \pm 0.04,0.33 \pm 0.03$, and $0.29 \pm 0.04$, respectively. 

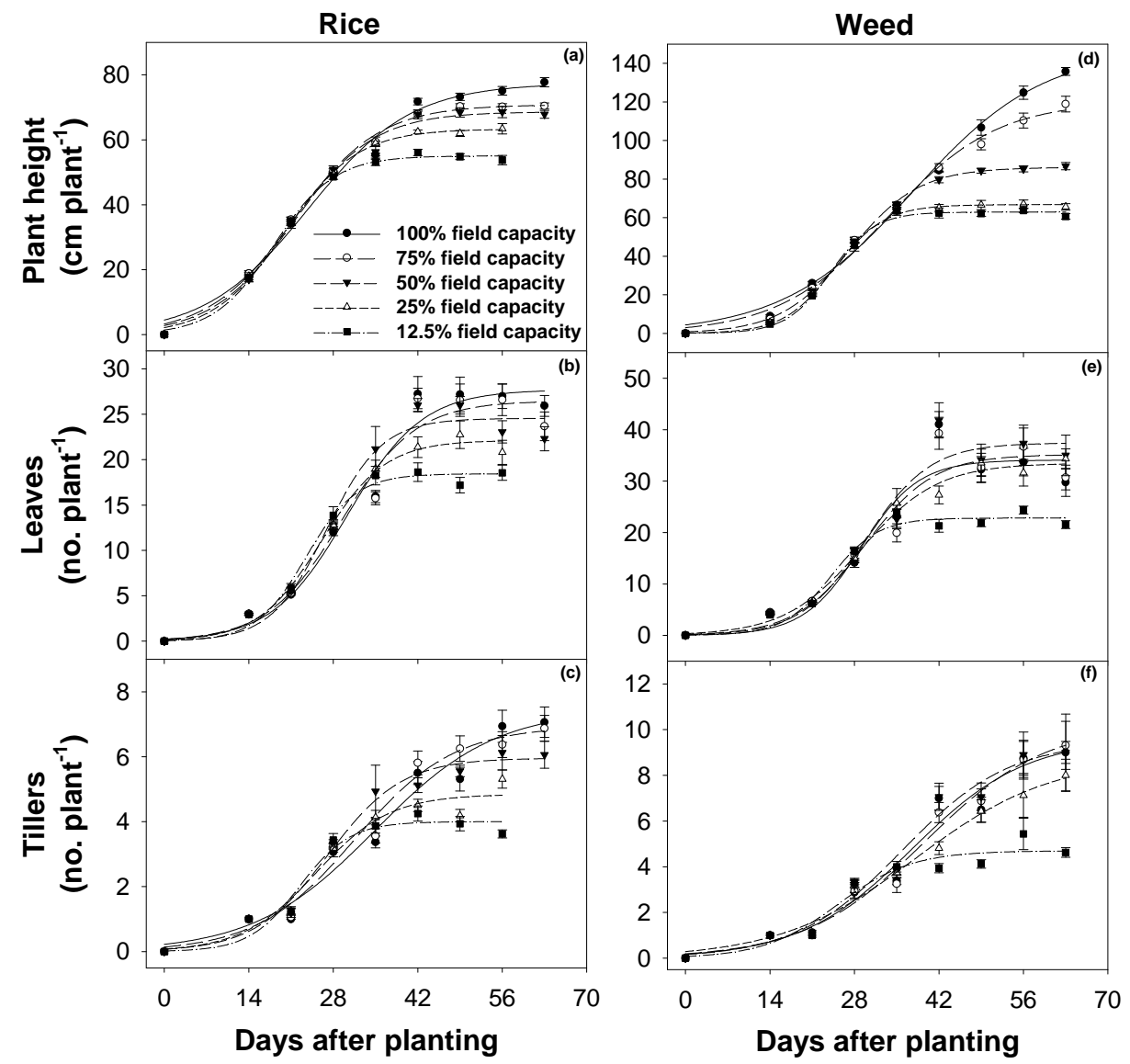

Figure 3. Height (a and d), number of leaves (b and e), and number of tillers (c and $f$ ) of rice and Leptochloa chinensis plants grown over $63 \mathrm{~d}$ after planting at different soil water contents. Water stress treatments were imposed at 7 days after planting and vertical bars represent standard error of mean $(n=8)$. The lines represent a three-parameter sigmoid model $(y=a /\{1+$ $\left.\left.\mathrm{e}^{[-(x-x 50) / b]}\right\}\right)$ fitted to the data. Parameter estimates are shown in Table 3.

Table 4. Parameter estimates of a three-parameter sigmoid model $\left(y=a /\left\{1+e^{[-(x-x 50) / b]}\right\}\right.$, where $a$ is the maximum biomass or leaf weight ratio; $x_{50}$ is the field capacity (\%) to reach $50 \%$ of the final biomass or leaf weight ratio; and $b$ is the slope at field capacity $x$ ) fitted to leaf, stem, and total shoot biomass and leaf weight ratio of rice and Leptochloa chinensis when grown at different soil water contents.

\begin{tabular}{|c|c|c|}
\hline Parameter estimates & Rice & Weed \\
\hline \multicolumn{3}{|l|}{ Leaf biomass (g plant $^{-1}$ ) } \\
\hline$a$ & $1.88(0.01)^{\mathrm{a}}$ & $4.51(0.07)$ \\
\hline$b$ & $1.2(0.1)$ & $15.4(0.8)$ \\
\hline$x_{50}$ & $48.6(0.1)$ & $39.3(1.0)$ \\
\hline$R^{2}$ & 0.99 & 0.99 \\
\hline \multicolumn{3}{|l|}{ Stem biomass ( g plant $^{-1}$ ) } \\
\hline$a$ & $3.06(0.13)$ & $3.56(0.04)$ \\
\hline$b$ & $6.1(3.3)$ & $15.0(0.5)$ \\
\hline$x_{50}$ & $47.6(1.8)$ & $47.0(0.7)$ \\
\hline$R^{2}$ & 0.99 & 0.99 \\
\hline \multicolumn{3}{|l|}{ Total shoot biomass $\left(\mathrm{g}\right.$ plant $\left.^{-1}\right)$} \\
\hline$a$ & $4.92(0.12)$ & $11.83(0.20)$ \\
\hline$b$ & $4.6(3.4)$ & $20.9(1.1)$ \\
\hline$x_{50}$ & $46.8(2.4)$ & $31.4(1.1)$ \\
\hline$R^{2}$ & 0.99 & 0.99 \\
\hline \multicolumn{3}{|l|}{ Leaf weight ratio $\left(\mathrm{g} \mathrm{g}^{-1}\right)$} \\
\hline$a$ & - & $0.39(0.01)$ \\
\hline$b$ & - & $12.72(1.38)$ \\
\hline$x_{50}$ & - & $12.01(0.90)$ \\
\hline$R^{2}$ & - & 0.99 \\
\hline
\end{tabular}

${ }^{\mathrm{a}}$ Values in parentheses are standard error of mean. -Models did not fit. 


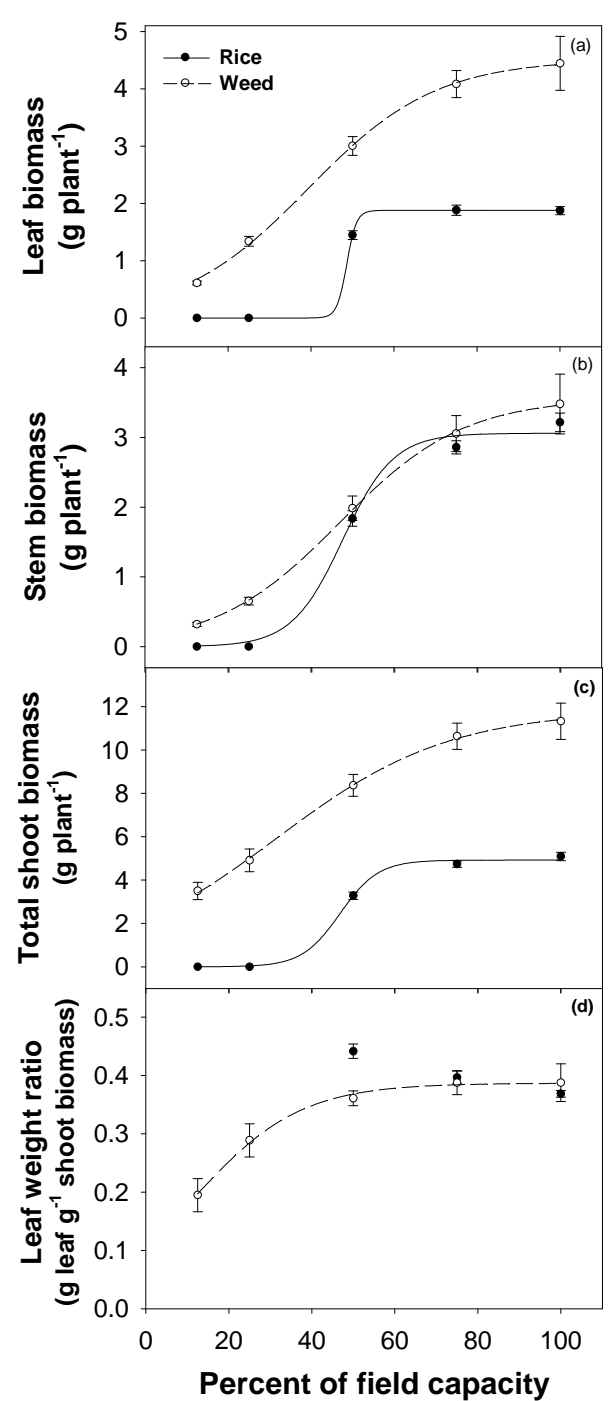

Figure 4. Leaf (a), stem (b), and total shoot (c) biomass and leaf weight ratio (d) of rice andLeptochloa chinensis plants (at 63 days after planting) grown in different field capacity regimes. Vertical bars represent standard error of mean (n $=8$ ). The lines represent a three-parameter sigmoid model $\left(y=a /\left\{1+e^{[-(x-x 50) / b]}\right\}\right)$ fitted to the leaf, stem, and total shoot biomass and leaf weight ratio of rice and $L$. chinensis when grown at different soil water contents. Parameter estimates are shown in Table 4.

\section{Discussion}

We studied the growth of A. spinosus and L. chinensis in two experiments, in which these weeds were grown with rice plants at different moisture content. Rice plants in both experiments could not survive at $25 \%$ and $12.5 \%$ of FC; however, both weeds survived at these field capacities. The plants in our study were irrigated at an interval of 3 days. In field conditions in the rainfed environment, rain may be sporadic and a longer dry spell, coupled with high temperatures, may cause rice plants to die even earlier than observed in our greenhouse study. Compared with the rice plants, the weeds in both experiments survived until their maturity. Such information suggests that, compared with both weed species, the rice cultivars (Apo and Rc222) used in our study were less tolerant of high water stress. The number of rice tillers and leaves was lower in the A. spinosus experiment than in the $L$. chinensis experiment. This response could be due to different rice cultivars used in our study.

In previous studies, rice grew best at $120 \%$ to $160 \%$ of $\mathrm{FC}$ and rice was more competitive than weeds with sufficient moisture, but weeds were more competitive than rice with water stress $[23,24]$. In water-limited environments, weeds may have higher leaf water potential than rice, suggesting that a limited amount of water in soil would benefit weeds more than rice [25]. In another study, too, A. spinosus had higher water potential values than the rice in both well-watered and water-stress treatments [13]. Such information, however, was not found for L. chinensis.

Our study observed that, regardless of FC, weed plants were taller than the rice plants. These observations are supported by field observations of $A$. spinosus and $L$. chinensis often visible above the rice canopy in commercial fields, especially where there is a gap between rice plants (i.e., poor plant population). In the crop, these weeds may grow taller than rice to take advantage of the higher light intensity as $\mathrm{C}_{4}$ plants and, at the same time, shading rice $[13,26,27]$. Both weeds produced a considerable number of leaves and tillers/branches, even at $50 \%$ or less FC. Usually, the time taken to reach $50 \%$ of the maximum leaves and tillers/branches was less at $25 \%$ and $12.5 \%$ of FC compared with $50 \%$ or higher FC. These responses were not due to early leaf or tiller/ branch production at $12.5 \%$ or $25 \%$ of FC but rather to the lack of an increase in leaf and tiller/branch number beyond 35 DAP. Similar results were reported in a similar study on Rottboellia cochinchinensis (Lour.) W. D. Clayton (itchgrass) [5].

Compared with that of rice, total shoot biomass was higher in weeds at all the levels of FC. At 100\% of FC, for example, weed biomass was 2.5 to 3 times more than rice biomass. Both weeds produced a significant amount of biomass at $12.5 \%$ and $25 \%$ of $\mathrm{FC}$; however, rice did not survive at these moisture contents. These results again suggest that $A$. spinosus and $L$. chinensis are more tolerant of water stress than rice. These observations were also supported by the parameter estimates fitted to the biomass data. In the A. spinosus experiment, the FC to achieve $50 \%$ of the maximum biomass $\left(x_{50}\right)$ was $50 \%$ for rice, whereas this value for $A$. spinosus was only $39 \%$ of FC. Similarly, in the L. chinensis experiment, the $x_{50}$ values were $47 \%$ for rice and $31 \%$ for $L$. chinensis. An earlier study [5] reported $R$. cochinchinensis to be more tolerant than the weeds included in our study. Compared 
with $100 \%$ of FC, the aboveground biomass of $R$. cochinchinensis declined by only $54 \%$ at $25 \%$ of FC. However, the weed plants were grown without rice and there was only one plant per pot. High plant density may deplete moisture content much faster than with low plant density.

As rice did not survive at the lowest two levels of SWC, its leaf weight ratio could not be analyzed using regression analysis. However, the leaf weight ratio data in both experiments at other $\mathrm{FC}(50 \%, 75 \%$, and $100 \%)$ indicated that rice plants responded with increased leaf weight ratio to increases in water stress. Both weed species responded differently to water stress. Similar to rice, A. spinosus plants responded with increased leaf weight ratio to a decrease in SWC (or increase in water stress). These results suggest that $A$. spinosus under water stress conditions allocated more biomass to the leaf than to other shoot parts, and this could be a survival strategy in water-limited environments. Similar results were reported for $R$. cochinchinensis, in which leaf weight ratio at $12.5 \%$ of FC was 2.5 times greater than at $100 \%$ of FC [5]. In contrast to $R$. cochinchinensis and A. spinosus, $L$. chinensis responded with decreased leaf weight ratio to an increase in water stress or decrease in SWC. These results suggest that $L$. chinensis under water stress conditions allocated more biomass to other shoot parts than to the leaf. Inflorescence weight ratio data suggest that $L$. chinensis allocated more biomass to the inflorescence than to leaf and stem parts. The inflorescence weight ratio was around two times more at $25 \%$ of $\mathrm{FC}$ than at $100 \%$ of FC. Although we did not determine the seed production of these weed species in different water stress treatments (the seed size was very small), the inflorescence data suggest that $L$. chinensis can produce a considerable amount of seeds, even at high water stress. In earlier studies, R. cochinchinensis and Echinochloa colona produced a small amount of seeds even at $12.5 \%$ of FC and the authors suggested that the amount of seeds per plant may be enough to cause heavy infestations in the next growing seasons $[5,20]$. The ability of the weeds to produce seeds in water-limited conditions would help L. chinensis to survive in an unpredictable environment.

The results of our study demonstrated that $A$. spinosus and $L$. chinensis are more tolerant of water stress than the rice crop. As mentioned earlier, both weed species utilize a $\mathrm{C}_{4}$ photosynthetic pathway and rice belongs to the $\mathrm{C}_{3}$ group. The $\mathrm{C}_{4}$ photosynthetic pathway overcomes the limitation of the photorespiration, improves photosynthetic efficiency, and minimize the water loss in hot, dry environments $[28,29]$. In a previous study, Ozturk and colleagues [30] studied the effect of water availability on competition between $\mathrm{C}_{3}$ and $\mathrm{C}_{4}$ species and concluded that $\mathrm{C}_{3}$ species were least productive under dry conditions. If weeds utilize water more efficiently than rice, then a limited amount of water in soil would benefit the weeds more than the crop [23]. There is a need to breed improved rice cultivars tolerant of water stress. Weed infestation in water-limited environments may decrease rice yield in addition to the effect of water stress on the rice crop. Therefore, it is important to control weeds in the early stages of crop growth and preserve moisture for the crops. Post-emergence herbicide efficacy may be less in water-stressed conditions, mainly because of less herbicide absorption. An earlier study showed that the doses of herbicides to effectively control Commelina bengha- lensis L. (Bengal dayflower) increased upto 250 times at $25 \%$ of FC compared with herbicide application at $100 \%$ of FC [31]. Weed plants may develop a thicker leaf cuticle in water-stressed conditions, and the thick cuticle may reduce herbicide entry into the leaf $[8,32]$. Therefore, any weed plants escaping after herbicide application in water-stressed fields should be removed to prevent future infestation.

Asia has a significant amount of water-limited area and this is likely to increase in the future. In rainfed and drought-prone rice areas, not much attention has been given to managing weeds. There is a need to focus research in such areas on understanding the effects of water stress on weed-rice competition and on improving herbicide efficacy in rice weeds. Such research becomes more important in the changing climates cenario. There is a need to exploit weed management strategies, including the use of weed-competitive and drought-tolerant cultivars, high seeding rates, and optimum timing of fertilizers, to minimize weed survival in water-limited environments.

\section{Acknowledgements}

We gratefully acknowledge Dr. Bill Hardy for providing comments on the manuscript.

\section{REFERENCES}

[1] R. E. Huke and E. H. Huke, "Rice Area by Type of Culture: South, Southeast, and East Asia," International Rice Research Institute, Los Baños, 1997.

[2] A. Kumar, S. Verulkar, S. Dixit, B. Chauhan, J. Bernier, R. Venuprasad, D. Zhao and M. N. Shrivastava, "Yield and Yield-Attributing Traits of Rice (Oryza sativa L.) under Lowland Drought and Suitability of Early Vigor as a Selection Criterion,” Field Crops Research, Vol. 114, No. 1, 2009, pp. 99-107. doi:10.1016/j.fcr.2009.07.010

[3] S. Pandey, H. Bhandari and B. Hardy, "Economic Costs of Drought and Rice Farmers' Coping Mechanisms: A Cross-Country Comparative Analysis," International Rice Research Institute, Los Baños, 2007, p. 203.

[4] T. P. Tuong and B. A. M. Bouman, "Rice Production in Water-Scarce Environments," In: J. W. Kijne, R. Barker and D. Molden, Eds., Water Productivity in Agriculture: Limits and Opportunities for Improvements, CABI Publishing, 2003, pp. 53-67. doi:10.1079/9780851996691.0053 
[5] B. S. Chauhan, "Growth Response of Itchgrass (Rottboellia cochinchinensis) to Water Stress," Weed Science, Vol. 61, No. 1, 2013, pp. 98-103. doi:10.1614/WS-D-12-00060.1

[6] T. M. Webster and T. L. Grey, "Growth and Reproduction of Benghal Dayflower (Commelina benghalensis) in Response to Drought Stress," Weed Science, Vol. 56, No. 4, 2008, pp. 561-566. doi:10.1614/WS-07-186.1

[7] B. S. Chauhan, "Weed Ecology and Weed Management Strategies for Dry-Seeded Rice in Asia," Weed Technology, Vol. 26, No. 1, 2012, pp. 1-13. doi:10.1614/WT-D-11-00105.1

[8] D. T. Patterson, "Weeds in a Changing Climate," Weed Science, Vol. 43, No. 4, 1995, pp. 685-701.

[9] B. S. Chauhan and D. E. Johnson, "Germination Ecology of Chinese Sprangletop (Leptochloa chinensis) in the Philippines," Weed Science, Vol. 56, No. 6, 2008, pp. 820-825. doi:10.1614/WS-08-070.1

[10] B. S. Chauhan and D. E. Johnson, "Germination Ecology of Spiny (Amaranthus spinosus) and Slender Amaranth (A. viridis): Troublesome Weeds of Direct Seeded Rice," Weed Science, Vol. 57, No. 4, 2009, pp. 379-385. doi:10.1614/WS-08-179.1

[11] B. S. Chauhan and D. E. Johnson, "Row Spacing and Weed Control Timing Affect Yield of Aerobic Rice," Field Crops Research, Vol. 121, No. 2, 2011, pp. 226-231. doi:10.1016/j.fcr.2010.12.008

[12] B. S. Chauhan and J. Opeña, "Effect of Tillage Systems and Herbicides on Weed Emergence, Weed Growth, and Grain Yield in Dry-Seeded Rice Systems," Field Crops Research, Vol. 137, 2012, pp. 56-69. doi:10.1016/j.fcr.2012.08.016

[13] R. T. Cruz, J. C. O’Toole and K. Moody, "Leaf Water Potential of Weeds and Rice (Oryza sativa)," Weed Science, Vol. 31, No. 3, 1983, pp. 410-414.

[14] A. N. Rao, D. E. Johnson, B. Sivaprasad, J. K. Ladha and A. M. Mortimer, "Weed Management in Direct-Seeded Rice," Advances in Agronomy, Vol. 93, 2007, pp. 153255. doi:10.1016/S0065-2113(06)93004-1

[15] M. Azmi, D. V. Chin, P. Vongsaroj and D. E. Johnson, "Emerging Issues in Weed Management of Direct-Seeded Rice in Malaysia, Vietnam, and Thailand," Rice Is Life: Scientific Perspectives for the 21st Century, International Rice Research Institute and Tsukuba, Los Baños, Japan International Research Center for Agricultural Sciences, Japan, 2005, pp. 196-198.

[16] B. Marambe, "Emerging Weed Problems in Wet-Seeded Rice Due to Herbicide Use in Sri Lanka," Abstracts: International Rice Congress, Beijing, 14-19 October 2002, p. 430.

[17] J. R. Ehleringer, T. E. Cerling and B. R. Helliker, " $\mathrm{C}_{4}$ Photosynthesis, Atmospheric $\mathrm{CO}_{2}$ and Climate," Oecologia, Vol. 112, No. 3, 1997, pp. 285-299. doi:10.1007/s004420050311

[18] J. Fuhrer, "Agroecosystem Reponses to Combinations of Elevated $\mathrm{CO}_{2}$, Ozone, and Global Climate Change," Agriculture, Ecosystems and Environment, Vol. 97, No. 1-3, 2003, pp. 1-20. doi:10.1016/S0167-8809(03)00125-7
[19] X. Yin and P. C. Struik, "Applying Modelling Experiences from the Past to Shape Crop Systems Biology: The Need to Converge Crop Physiology and Functional Genomics," New Phytologist, Vol. 179, No. 3, 2008, pp. 629-642. doi:10.1111/j.1469-8137.2008.02424.x

[20] B. S. Chauhan and D. E. Johnson, "Growth and Reproduction of Junglerice (Echinochloa colona) in Response to Water-Stress," Weed Science, Vol. 58, No. 2, 2010, pp. 132-135. doi:10.1614/WS-D-09-00016.1

[21] K. J. Steadman, A. J. Ellery, R. Chapman, A. Moore and N. C. Turner, "Maturation Temperature and Rainfall Influence Seed Dormancy Characteristics of Annual Ryegrass (Lolium rigidum)," Australian Journal of Agricultural Research, Vol. 55, No. 10, 2004, pp. 1047-1057. doi:10.1071/AR04083

[22] GenStat 8.0, "GenStat Release 8 Reference Manual," VSN International, Oxford, 2005, p. 343.

[23] J. D. Janiya and K. Moody, "Effect of Water Deficit on Rice-Weed Competition under Greenhouse Conditions," Journal of Plant Protection in the Tropics, Vol. 8, No. 1, 1991, pp. 25-35.

[24] R. L. Zimdahl, K. Moody and R. C. Chavez, "The Influence of Soil Moisture on Growth of Some Rice (Oryza sativa) Weeds," Philippines Journal of Weed Science, Vol. 14, No. 1, 1987, pp. 19-25.

[25] K. Moody and J. D. Janiya, "Effect of Weather on Weeds and Their Control with Herbicides," In: Weather and Rice, International Rice Research Institute, Los Baños, 1987, pp. 165-174.

[26] B. S. Chauhan and S. B. Abugho, "Phenotypic Plasticity of Spiny Amaranth (Amaranthus spinosus) and Longfruited Primrose-Willow (Ludwigia octovalvis) in Response to Rice Interference," Weed Science, Vol. 60, No. 3, 2012, pp. 411-415. doi:10.1614/WS-D-11-00158.1

[27] B. S. Chauhan and D. E. Johnson, "Phenotypic Plasticity of Chinese Sprangletop (Leptochloa chinensis) in Competition with Seeded Rice," Weed Technology, Vol. 25, No. 4, 2011, pp. 652-658. doi:10.1614/WT-D-09-00076.1

[28] G. E. Edwards and D. A. Walker, " $\mathrm{C}_{3}, \mathrm{C}_{4}$ : Mechanisms, and Cellular and Environmental Regulation of Photosynthesis," Blackwell Scientific, Oxford, 1983.

[29] M. V. Lara and C. S. Andrea, " $\mathrm{C}_{4}$ Plants Adaptation to High Levels of $\mathrm{CO}_{2}$ and to Drought Environments," In: A. Shanker, Ed., Abiotic Stress in Plants-Mechanisms and Adaptations, InTech, 2011, pp. 415-428.

[30] M. Ozturk, H. Rehder and H. Zeigler, "Biomass Production of $\mathrm{C}_{3}$ and $\mathrm{C}_{4}$ Plants Species in Pure and Mixed Culture with Different Water Supply," Oecologia, Vol. 50, No. 1, 1981, pp. 73-81. doi:10.1007/BF00378796

[31] P. J. Steptoe, W. K. Vencill and T. L. Grey, "Influence of Moisture Stress on Herbicidal Control of an Invasive Weed, Benghal Dayflower (Commelina benghalensis)," Journal of Plant Diseases and Protection, Vol. 20, 2006, pp. 907-914.

[32] D. T. Patterson, "Effects of Environmental Stress on Weed/Crop Interactions," Weed Science, Vol. 43, No. 3, 1995, pp. 483-490. 